Original article

\title{
ANTIBACTERIAL ACTIVITY OF ZIZIPHORA CLINOPODIOIDES ESSENTIAL OIL AND NISIN AGAINST BACILLUS SUBTILIS AND SALMONELLA TYPHIMURIUM IN COMMERCIAL BARLEY SOUP
}

\author{
Y. SHAHBAZI ${ }^{1}$, N. SHAVISI ${ }^{2} \&$ E. MOHEBI ${ }^{1}$ \\ ${ }^{1}$ Department of Food Hygiene and Quality Control, Faculty of Veterinary \\ Medicine, Razi University, Kermanshah, Iran; ${ }^{2}$ Department of Food Hygiene \\ and Quality Control, Faculty of Veterinary Medicine, University of Tehran, \\ Tehran, Iran
}

\section{Summary}

Shahbazi, Y., N. Shavisi \& E. Mohebi, 2017. Antibacterial activity of Ziziphora clinopodioides essential oil and nisin against Bacillus subtilis and Salmonella Typhimurium in commercial barley soup. Bulg. J. Vet. Med., 20, No 1, 65-72.

The objective of the current study was to evaluate the antibacterial activity of nisin (250 and 500 $\mathrm{IU} / \mathrm{mL})$, Ziziphora clinopodioides essential oil $(0.1$ and $0.2 \%)$ and their combination against Bacillus subtilis and Salmonella Typhimurium in commercial barley soup during refrigerated storage. Based on our findings, the population of pathogens was reduced with the addition of the essential oil and nisin, increased concentration of the added antibacterial agents and the longer storage time of commercial barley soup. The group treated with the essential oil at $0.2 \%$ and nisin at $500 \mathrm{IU} / \mathrm{mL}$ showed the most rapid decrease in the number of $S$. Typhimurium and $B$. subtilis. By the end of seven and five days, populations of $S$. Typhimurium and $B$. subtilis in overall concentrations of the essential oil with nisin were totally inhibited, respectively. Our findings suggest the possibility of utilising commercial barley soup with a mixture of $Z$. clinopodioides essential oil and nisin for the reduction of $B$. subtilis and $S$. Typhimurium.

Key words: antibacterial activity, Bacillus subtilis, barley soup, nisin, Salmonella Typhimurium, Ziziphora clinopodioides essential oil

\section{INTRODUCTION}

Barley soup is one of the most commonly consumed foods in many Mediterranean countries such as Iran. It is prepared by boiling different meat such as chicken, beef or lamb with barley, adding a variety of vegetables and a little salt (Moosavy et $a l ., 2008)$. It is, due to special and different compounds such as onion, meat, carrot, parsley and barley, a rich source of high quality protein, vitamins and minerals and make appropriate medium for growth of food-borne pathogens and 
spoilage microorganisms (Pajohi et al., 2011). The major bacterial food-borne pathogens in soup include Salmonella spp., Staphylococcus aureus, some Escherichia coli especially E. coli O157:H7, Bacillus cereus and Bacillus subtilis (Siddiqua et al., 2015). The genus Salmonella has caused a large proportion of food-borne outbreaks in different geographic areas. Some serovars like $S$. Typhimurium became a main cause of animal and human infection (Bajpai et al., 2012). Some foods such as meat, unpasteurised milk and dairy products and commercial barley soup contaminated with Salmonella bacteria were found to play a great role in increasing food poisoning outbreaks in people, in particular those with weakened immune systems and children (Humphrey \& Jorgensen, 2006; Bajpai et al., 2012). On the other hands, B. subtilis, a rod shape spore forming Gram-positive bacterium, can produce emetic toxin and then cause intoxication in humans. The vehicles include meat, seafood dishes, commercial barley soup, rice and bread. The symptoms are vomiting, diarrhoea, abdominal pain, cramps, nausea, headaches with duration of 2-7 h (Riemann \& Cliver, 2013).

A lot of studies have been done to make new natural preservation methods in an attempt to control food-borne pathogens while keeping a high organoleptical and nutritional quality of the food products (Devlieghere et al., 2004). In this way, attempts have been focused on the potential applications of essential oils of various plants. Ziziphora clinopodioides is a plant belonging to the Lamiaceae family that widely distributed in Turkey, Iraq and west of Iran (Schulz et al., 2005; Behravan et al., 2007; Ozturk \& Ercisli, 2007). This plant with a Persian name of Kakouti Kouhi is traditionally used to treat diar- rhoea, intestinal gas, nausea and vomiting. In addition, it used as flavour ingredient in a wide variety of foods especially meat and soup (Behravan et al., 2007; Shahbazi et al., 2015a). The major constituents of the essential oil of this plant are thymol, carvacrol, $p$-cymene and limonene (Shahbazi et al., 2015a,b).

To demonstrate the potential application of natural antimicrobial agents in food industries, they must be examined separately and in combination with other antimicrobial preservative agents such as nisin (Shahbazi et al., 2015a). Nisin (E234) is classified as a class-Ia bacteriocin or lantibiotic and produced by strains of Lactococcus lactis subsp. lactis or Streptococcus uberis. This compound affects the wide spectrum of Grampositive bacteria and some of Gramnegative bacteria by damaging the layer membrane of them (Govaris et al., 2010). Therefore, the aim of the present study was to investigate the antibacterial activity of nisin, Z. clinopodioides essential oil and their combination against B. subtilis and $S$. Typhimurium in commercial barley soup during refrigerated storage.

\section{MATERIALS AND METHODS}

\section{Plant material}

Three samples of fresh leaves (200 g each) of $Z$. clinopodioides plant were gathered from same location at full flowering stage in March-July 2014 from Zagros Mountain ranges (Gilane Gharb city, Kermanshah province, west of Iran). Authentication of the plant was conducted by Dr. Seyed Mohammad Masoumi (Faculty of Agriculture, Razi University, Kermanshah, Iran) and a representative voucher specimen (No. 6816) has been placed in the herbarium of the Research Center of Natural Resources of Tehran, Iran. 


\section{Isolation of essential oil}

The air-dried samples (100 g) of Z. clinopodioides leaves were hydro-distilled for $3.5 \mathrm{~h}$ in an all-glass Clevenger-type apparatus in accordance with the method described in the European Pharmacopoeia (Council of Europe, 1999). Heat was supplied to the heating mantle $\left(50^{\circ} \mathrm{C}\right)$ and the essential oil was extracted with $500 \mathrm{~mL}$ of water for $3.5 \mathrm{~h}$ (until no more essential oil was recovered). The essential oil was collected, dried over anhydrous sodium sulfate $\left(\mathrm{Na}_{2} \mathrm{SO}_{4}\right)$ (Merck, Darmstadt, Germany), stored in darkness in an amber vial and kept at low temperature $\left(4 \pm 1^{\circ} \mathrm{C}\right)$.

\section{Preparation of nisin}

Pure nisin powder was purchased from Sigma-Aldrich Company (UK). A stock suspension was prepared by dissolving appropriate amount of nisin in $0.02 \mathrm{M}$ $\mathrm{HCl}$, then the stock solution was centrifuged at $1500 \times \mathrm{g}$ for $20 \mathrm{~min}$, filtered by $0.22 \mu \mathrm{m}$ pore filter (Sigma-Aldrich, USA) and kept at $-20{ }^{\circ} \mathrm{C}$ until use (Shahbazi, 2015a).

\section{Test microorganisms}

Bacillus subtilis (ATCC 6633) and Salmonella Typhimurium (ATCC 14028) were obtained from the culture collection of the Iranian Research Organization for Science and Technology (IROST), Tehran, Iran. The cultures were stored frozen $\left(-20{ }^{\circ} \mathrm{C}\right)$ in Brain Heart Infusion broth (BHI; Merck, Darmstadt, Germany) medium containing $17 \%$ glycerol and reactivated by subculture twice before testing. The optical densities of the 20 hour-old bacterial cultures were evaluated by using a spectrophotometer at $600 \mathrm{~nm}$. A loopful of each stock culture was transferred to $10 \mathrm{~mL}$ BHI broth and incubated for $24 \mathrm{~h}$ at $37^{\circ} \mathrm{C}$. An inoculum with a population of pathogen cells of $5 \log \mathrm{CFU} / \mathrm{mL}$ was used for the inoculation of soup samples.

\section{Experimental design}

Barley soup was prepared by adding commercial barley powder soup purchased from a market of Kermanshah city, west of Iran to the $400 \mathrm{~mL}$ distilled water

Table 1. Concentrations of $Z$. clinopodioides essential oil and nisin in the different batches of commercial barley soup

\begin{tabular}{ll}
\hline Batch & \\
\hline Control & - \\
A & $0.1 \%$ Z. clinopodioides essential oil \\
B & $0.2 \%$ Z. clinopodioides essential oil \\
C & $250 \mathrm{IU} / \mathrm{mL}$ nisin \\
D & $500 \mathrm{IU} / \mathrm{mL}$ nisin \\
E & $0.1 \%$ Z. clinopodioides essential oil $+250 \mathrm{IU} / \mathrm{mL}$ nisin \\
F & $0.1 \%$ Z. clinopodioides essential oil $+500 \mathrm{IU} / \mathrm{mL}$ nisin \\
G & $0.2 \%$ Z. clinopodioides essential oil $+250 \mathrm{IU} / \mathrm{mL}$ nisin \\
H & $0.2 \%$ Z. clinopodioides essential oil $+500 \mathrm{IU} / \mathrm{mL}$ nisin \\
\hline
\end{tabular}


into $500 \mathrm{~mL}$ conical flask according to producer manual and then sterilised at $121{ }^{\circ} \mathrm{C}$ for $15 \mathrm{~min}$. After cooling, Z. clinopodioides essential oil $(0.1$ and $0.2 \%)$ and nisin (250 and $500 \mathrm{IU} / \mathrm{mL})$ separately and in combination were added. Therefore, for each experiment, nine batches (Batch A-Batch H) were designed as shown in Table 1 . Then, approximately 5 $\log \mathrm{CFU} / \mathrm{mL}$ of $B$. subtilis or S. Typhimurium separately were inoculated. The samples were kept at $4 \pm 1{ }^{\circ} \mathrm{C}$ for 9 days. The samples were withdrawn at 2-day interval to check the level of contamination by plate method using plate count agar in triplicate. The colonies grown after $24 \mathrm{~h}$ of incubation at $37{ }^{\circ} \mathrm{C}$ were counted and count was expressed as log $\mathrm{CFU} / \mathrm{mL}$.

\section{Statistical analysis}

SPSS 16.0 for Windows (SPSS, Chicago, IL, USA) software package was used for data analyses. Mean and standard deviations of each experiment were calculated and then were subjected to analysis of variance. Tukey's test and 2-way ANOVA at $95 \%$ confidence interval was used to determine mean differences among the treatments.

\section{RESULTS}

The results of the antimicrobial activity of $Z$. clinopodioides essential oil, nisin and their combination against $B$. subtilis and $S$. Typhimurium in commercial barley soup during storage at $4{ }^{\circ} \mathrm{C}$ are shown in Table 2 and 3. During storage of the control sample at refrigerated temperature, $B$. subtilis and $S$. Typhimurium populations decreased steadily with storage time and reached values of $4.01 \log \mathrm{CFU} / \mathrm{mL}$ and $3.78 \log \mathrm{CFU} / \mathrm{mL}$ at 9 days, respectively. Based on our findings, the population of pathogens decreased with the addition of the essential oil and nisin, increased concentration of the added antibacterial agents and the longer storage time of commercial barley soup. With respect to $S$. Typhimurium, the groups treated with nisin at concentration of 250 and 500 $\mathrm{IU} / \mathrm{mL}$ (Batches $\mathrm{C}$ and $\mathrm{D}$ ) had insignificantly $(\mathrm{P}>0.05)$ higher microbial counts. The group treated with the essential oil at $0.2 \%$ and nisin at $500 \mathrm{IU} / \mathrm{mL}$ (Batch $\mathrm{H}$ ) showed the most rapid decrease in the number of $S$. Typhimurium. A similar result was found about $B$. subtilis. In the case of B. subtilis, both concentrations of nisin, had inhibitory effect on the growth of this bacterium. By the end of seven and five days, populations of $S$. Typhimurium and $B$. subtilis in overall concentrations of the essential oil with nisin were totally inhibited, respectively. With respect to samples treated with the essential oil at $0.2 \%$ and nisin at $500 \mathrm{IU} / \mathrm{mL}$ (Batch $\mathrm{H}$ ), the difference between this group and other groups was larger than that of samples treated with $0.2 \%$ essential oil and nisin at $250 \mathrm{IU} / \mathrm{mL}$ (Batch $\mathrm{H})$. However, no significant differences were found $(\mathrm{P}>0.05)$. The antibacterial activity of the essential oil and nisin against growth of two selected pathogens was the most effective on B. subtilis.

\section{DISCUSSION}

In order to control and eliminate foodborne pathogens, various chemicals and synthetic compounds such as antibiotics as preservative have been used. In recent years, due to increasing concern of consumers related to safety of foods containing synthetic additives, many attempts have been made to replace these compounds with natural antimicrobial agents such as herbal extracts and essential oils and also 

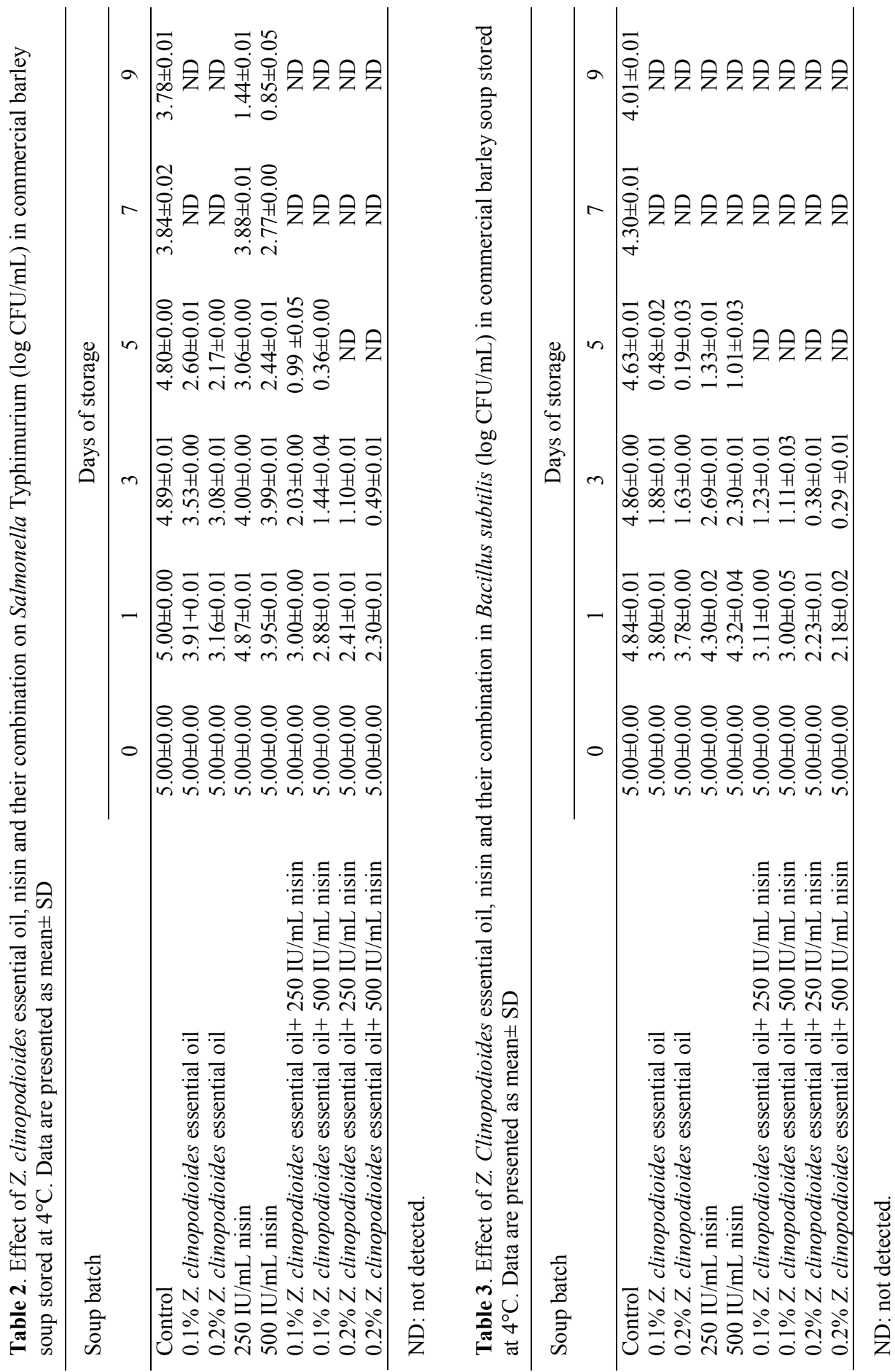

BJVM, 20, No 1 
several bacteriocins particularly nisin (Tajkarimi et al., 2010; Shahbazi, 2015c). In the present study, the antibacterial activity of nisin, Z. clinopodioides essential oil and their combination against B. subtilis and $S$. Typhimurium in commercial barley soup were investigated during refrigerated storage.

As previously described, the antibacterial activity of the essential oil and nisin against both selected pathogens was the most effective on B. subtilis. The differences in the inhibitory effects between $S$. Typhimurium and $B$. subtilis are related to their different cell wall structures. Indeed, generally the cell wall of Gram-positive bacteria consists of a single layer, whereas the Gram-negative cell wall has a multilayered structure bounded by an outer cell membrane (Kim et al., 2013). The antibacterial properties of $Z$. clinopodioides essential oil have been reported by other authors (Behravan et al., 2007; Ozturk \& Ercisli, 2007; Aghajani et al., 2008). The most important reason of the strong antibacterial activities of carvacrol and thymol is the acidic nature of their hydroxyl groups and involvement in the formation of hydrogen bonds (Cavar et al., 2008).

The results of the present study are in agreement with Moosavy et al. (2008) and Pajohi et al. (2011). Pajohi et al. (2011) found that the synergistic effect of the essential oil of Cuminum cyminum L. seed in combination with nisin at $0.25 \mu \mathrm{g} / \mathrm{ml}$ against $B$. subtilis in commercial barley soup. Moreover, Moosavy et al. (2008) reported significant inhibitory effect of Zataria multiflora Boiss. essential oil on $S$. Typhimurium and $S$. aureus in commercial barley soup. Except the described two earlier studies, several researches have reported the synergistic effect of nisin with various essential oils against common food-borne pathogenic bacteria such as Listeria monocytogenes (Yamazaki et al., 2004, Shahbazi, 2015a), E. coli O157:H7 (Solomakos et al., 2008; Saldaña et al., 2012; Shahbazi et al., 2015a), B. cereus (Periago \& Moezelaar, 2001; Rajkovic et al., 2005; Misaghi \& Basti, 2007), B. subtilis (Rajkovic et al., 2005) Salmonella spp. (Govaris et al., 2010; Saldaña et al., 2012) and S. aureus (Shahbazi et al., 2015a). It seems that essential oils enhance the effect of nisin by increasing the number of pores in the phospholipid bilayer membrane structure by nisin and also by increasing the size of the pores formed (Tajkarimi et al., 2010; Shahbazi et al., 2015b).

The results of the present study, for the first time, indicated that $Z$. clinopodioides essential oil in combination with nisin have inhibitory effects against $B$. subtilis and $S$. Typhimurium inoculated in commercial barley soup. Our findings suggest the possibility of utilising commercial barley soup with a mixture of $Z$. clinopodioides essential oil and nisin for the reduction of B. subtilis and $S$. Typhimurium.

\section{ACKNOWLEDGMENTS}

The authors would like to thank the authorities of the Faculty of Veterinary medicine, Razi University for their cooperation. This work was a section of research proposal in the research council of the Faculty of Veterinary Medicine, Razi University, Kermanshah, Iran (No.12.94.4431).

\section{REFERENCES}

Aghajani, Z., F. Assadian, S. Masoudi, F. Chalabian, A. Esmaeili, M. TabatabaeiAnaraki \& A. Rustaiyan, 2008. Chemical composition and in vitro antibacterial activities of the oil of Ziziphora clinopodioides and $Z$. capitata subsp. capitata from 
Iran. Chemistry of Natural Compounds, 44, 387-389.

Bajpai, V. K., K. H. Baek \& S. C. Kang, 2012. Control of Salmonella in foods by using essential oils: A review. Food Research International, 45, 722-734.

Behravan, J., M. Ramezani, M. Hassanzadeh, M. Eskandari, J. Kasaian \& Z. Sabeti, 2007. Composition, antimycotic and antibacterial activity of Ziziphora clinopodioides Lam. essential oil from Iran. Journal of essential oil-bearing plants, 10, 339-345.

Cavar, S., M. Maksimovic, M. E. Solic, A. Jerkovic-Mujkic \& R. Besta, 2008. Chemical composition and antioxidant and antimicrobial activity of two Satureja essential oils. Food Chemistry, 111, 648-653.

Council of Europe, 1999. European Pharmacopoeia. $3^{\text {rd }}$ edn, Royal Society of Medicine Press, Strasbourg, pp. 21-27.

Devlieghere, F., L. Vermeiren \& J. Debevere, 2004. New preservation technologies: Possibilities and limitations. International Dairy Journal, 14, 273-285.

Govaris, A., N. Solomakos, A. Pexara \& P. S. Chatzopoulou, 2010. The antimicrobial effect of oregano essential oil, nisin and their combination against Salmonella Enteritidis in minced sheep meat during refrigerated storage. International Journal of Food Microbiology, 137, 175-180.

Humphrey, T. \& F. Jorgensen, 2006. Review. Pathogens on meat infection in animals establishing a relationship using Campylobacter and Salmonella as examples. Meat Science, 74, 89-97.

Kim, S. J., A. R. Cho \& J. Han, 2013. Antioxidant and antimicrobial activities of leafy green vegetable extracts and their applications to meat product preservation. Food Control, 29, 112-120.

Misaghi, A. \& A. A. Basti, 2007. Effects of Zataria multiflora Boiss. essential oil and nisin on Bacillus cereus ATCC 11778. Food Control, 18, 1043-1049.

Moosavy, M. H., A. A. Basti, A. Misaghi, T. Z. Salehi, R. Abbasifar, H. A. E. Mousavi,
M. Alipour, N. E. Razavi, H. Gandomi \& N. Noori, 2008. Effect of Zataria multiflora Boiss. essential oil and nisin on Salmonella Typhimurium and Staphylococcus aureus in a food model system and on the bacterial cell membranes. Food Research International, 41, 1050-1057.

Ozturk, S. \& S. A. Ercisli, 2007. Antibacterial activity and chemical constitutions of Ziziphora clinopodioides. Food Control, 18, 535-540.

Pajohi, M. R., H. Tajik, A. A. Farshid \& M. Hadian, 2011. Synergistic antibacterial activity of the essential oil of Cuminum cyminum L. seed and nisin in a food model. Journal of Applied Microbiology, 110, 943-951.

Periago, P. M. \& R. Moezelaar, 2001. Combined effect of nisin and carvacrol at different $\mathrm{pH}$ and temperature levels on the viability of different strains of Bacillus cereus. International Journal of Food Microbiology, 68, 141-148.

Rajkovic, A., M. Uyttendaele, T. Courtens \& J. Debevere, 2005. Antimicrobial effect of nisin and carvacrol and competition between Bacillus cereus and Bacillus circulans in vacuum-packed potato puree. Food Microbiology, 22, 189-197.

Riemann, H. P. \& D. O. Cliver, 2013. Foodborne infections and intoxications. In: Infections with Other Bacteria. $4^{\text {th }}$ edn, Amsterdam, the Netherlands, pp. 341-366.

Saldaña, G., S. Monfort, S. Condón, J. Raso \& I. Álvarez, 2012. Effect of temperature, $\mathrm{pH}$ and presence of nisin on inactivation of Salmonella Typhimurium and Escherichia coli $\mathrm{O} 157: \mathrm{H} 7$ by pulsed electric fields. Food Research International, 45, 10801086.

Siddiqua, S., B. A. Anusha, L. S. Ashwini \& P. S. Negi, 2015. Antibacterial activity of cinnamaldehyde and clove oil: Effect on selected foodborne pathogens in model food systems and watermelon juice. Journal of Food Science and Technology, 52, 5834-5841. 
Antibacterial activity of Ziziphora clinopodioides essential oil and nisin against Bacillus subtilis and ....

Schulz, H., G. Özkan, M. Baranska, H. Kruger \& M. Özcan, 2005. Characterisation of essential oil plants from Turkey by IR and Raman spectroscopy. Vibrational Spectroscopy, 39, 249-256.

Shahbazi, Y. 2015a. Antilisterial effects of Ziziphora clinopodioides essential oil and nisin in milk. Journal of Pure and Applied Microbiology, 9, 1993-1999.

Shahbazi, Y. 2015b. Chemical composition and in vitro antibacterial effect of $\mathrm{Zizi}$ phora clinopodioides essential oil. Pharmaceutical Science, 21, 51-56.

Shahbazi, Y., 2015c. Chemical composition and in vitro antibacterial activity of Mentha spicata essential oil against common food-borne pathogenic bacteria. Journal of Pathogens, http://dx.doi.org/10.1155/ 2015/916305.

Shahbazi, Y., N. Shavisi \& E Mohebi, 2015a. Effects of Ziziphora clinopodioides essential oil and nisin, both separately and in combination, to extend shelf life and control Escherichia coli O157: $\mathrm{H} 7$ and Staphylococcus aureus in raw beef patty during refrigerated storage. Journal of Food Safety, DOI: 10.1111/jfs.12235.

Shahbazi, Y., N. Shavisi, N. Karami \& S. Kakaei, 2015b. Chemical composition and in vitro antibacterial activity of Ferulago angulata (Schlecht) Boiss essential oil. Pharmaceutical Sciences, 21, 6-11.

Solomakos, N., A. Govaris, P. Koidis \& N. Botsoglou, 2008. The antimicrobial effect of thyme essential oil, nisin, and their combination against Listeria monocyto- genes in minced beef during refrigerated storage. Food Microbiology, 25, 120-127.

Tajkarimi, M. M., S. A. Ibrahim \& D. O. Cliver, 2010. Antimicrobial herb and spice compounds in food. Food Control, 21, 1199-1218.

Yamazaki, K., T. Yamamoto, Y. Kawai \& N. Inoue, 2004. Enhancement of antilisterial activity of essential oil constituents by nisin and diglycerol fatty acid ester. Food Microbiology, 21, 283-289.

Paper received 03.07.2015; accepted for publication 12.11.2015

\section{Correspondence:}

Dr. Yasser Shahbazi, Department of Food Hygiene and Quality Control,

Faculty of Veterinary Medicine, Razi University,

Kermanshah, 671568-5414, Iran

Tel: 00988338324042

Fax: 00988338320041

e-mail: yasser.shahbazi@yahoo.com, y.shahbazi@razi.ac.ir 